\title{
Study on effects of E-glass fiber hybrid composites enhanced with multi-walled carbon nanotubes under tensile load using full factorial design of experiments
}

\author{
Md Musthak $^{1} \cdot$ M. Madhavi ${ }^{2}$ F. M. Ahsanullah ${ }^{3}$
}

Received: 8 March 2017/ Accepted: 28 April 2017/Published online: 20 May 2017

(c) The Author(s) 2017. This article is an open access publication

\begin{abstract}
Carbon nanotubes (CNT's) are attracting scientific and industrial interest by virtue of their outstanding characteristics. The present research problem deals with the fabrication and characterization of E-glass fiber composites enhanced by carbon nanotubes. In the present study, three factors with two levels are considered. Hence, the design is called $2^{3}$ full factorial design of experiment. The process parameters considered for the present problem are weight of multi-walled carbon nanotubes, process to disperse nano-particles in resin, and orientation of woven fabric. In addition, their levels considered for the experiment are higher level $(+1)$ and lower level $(-1)$. Fabrication of E-glass fiber composites was carried out according to design, and the specimens were prepared with respect to the ASTM standards D3039-76 and tensile testing was performed. The results show that the nano-particulated composite plate can be manufactured by considering lower level nano-particles stirred with probe sonicator and pliedup with hybrid orientation.
\end{abstract}

Keywords Carbon nanotubes - Composite materials · Characterization of materials

Md Musthak

musthak.mech@gmail.com

1 Department of Mechanical Engineering, Deccan College of Engineering and Technology, Hyderabad, Telangana, India

2 Department of Mechanical Engineering, M.V.S.R. Engineering College, Hyderabad, Telangana, India

3 Department of Industrial Engineering, University of Texas, Arlington, TX 76019, USA

\section{Introduction}

Fiber-reinforced composite materials have gained popularity (despite high cost) in high-performance products that needs to be lightweight, strong enough to take aerial loading conditions such as aerospace components, boat and scull hulls, bicycle frames, and racing car bodies. Other uses include fishing rods, storage tanks, and baseball bats (Abrate 1991; Cantwell and Morton 1991; Richardson and Wisheart 1996; Bibo and Hogg 1996; Naik et al. 2000). The new Boeing 787 structure including the wings and fuselage is composed largely of composites (Davies et al. 1996). Composite materials are also becoming more common in the realm of orthopedic surgery. In aerospace industry, there is huge demand for low density and low cost materials with better mechanical properties. In this view, there are many researchers developed new materials interms of composites.

Carbon composite is a key material in today's launch vehicles and heat shields for the re-entry phase of spacecraft. It is widely used in solar panel substrates, antenna reflectors, and yokes of spacecraft (Lifshitz and Gandelsman 1997). It is also used in payload adapters, inter-stage structures, and heat shields of launch vehicles. To ensure effective reinforcements for polymer composites, proper dispersion and good interfacial bonds between CNT's and polymer matrix have to be guaranteed.

\section{Materials and processes}

\section{E-glass/epoxy}

E-glass/epoxy, an individual structural glass fiber is both stiff and strong in tension and compression along its axis. Although it might be assumed that the fiber is weak in compression, it is 
actually only the long aspect ratio of the fiber which makes it seem so; i.e., because a typical fiber is long and narrow, it buckles easily (Ebeling et al. 1997). Polymers are substances, which consist of long chains or networks, built up by the repeated linkage of small reactive molecules. With a clearer understanding of the chemistry and physics of materials such as plastics, rubber, adhesives, and coatings it has become possible to combine them with fibers to produce an enormous range of unknown substances which are loosely referred to as “advanced composites” Hirai et al. (1998a).

\section{Polymer matrix nanocomposites}

In the simplest case, it should be noted that the improvement in mechanical properties may not be limited to stiffness or strength. Time-dependent properties could be improved by addition of nanofillers (Hirai et al. 1998b). Alternatively, the enhanced crystallization behavior under flow conditions and other physical properties of high-performance nanocomposites may be mainly due to the high aspect ratio and/or the high surface area of the fillers, since nanoparticulates have extremely high surface area to volume ratios when good dispersion is achieved. Nanoparticle dispersibility in the polymer matrix is a key issue, which limits the applicable particle volume fraction and therefore also the multi-functionality of the composite material (Choi et al. 1991).

The E-glass fiber is considered in the present study with a size of 600 yields (600 yards in one pound of material) and the multi-walled carbon nanotubes with properties given in Table 1 were considered for the present study. The room temperature curable Epoxy Resin LAPOX L-12 and Hardener K-6 are used as matrix material in the experimentation.

\section{Design of experiments}

To understand a DOE, it is necessary to understand the process. A process is the transformation of inputs into outputs. In the context of manufacturing, inputs are factors

Table 1 Properties of carbon nanotubes

\begin{tabular}{ll}
\hline Diameter & $8-15 \mathrm{~nm}$ \\
Length & $10-50 \mu \mathrm{m}$ \\
Purity & $95 \%$ \\
Ash & $<1.5 \%$ \\
\hline
\end{tabular}

Table $32^{3}$ Two-level, full factorial design table showing runs in 'standard order'

\begin{tabular}{llll}
\hline Experiment & $\mathrm{A}$ & $\mathrm{B}$ & $\mathrm{C}$ \\
\hline 1 & -1 & -1 & -1 \\
2 & +1 & -1 & -1 \\
3 & -1 & +1 & -1 \\
4 & +1 & +1 & -1 \\
5 & -1 & -1 & +1 \\
6 & +1 & -1 & +1 \\
7 & -1 & +1 & +1 \\
8 & +1 & +1 & +1 \\
\hline
\end{tabular}

or process parameters such as people, materials, methods, machines, etc. and outputs can be performance, characteristics or quality of a product. Three factors with two levels are considered for the present study. Hence the design is called as $2^{3}$ full factorial design. The list of process parameters and their levels for the experiment are presented in Table 2.

To identify the significant main effects, it is decided to construct an experimental layout as shown in Table 3. The parameter $\mathrm{C}$ is considered with only one level, whereas the factors $\mathrm{R}, \mathrm{P}$, and $\mathrm{O}$ are considered at two levels-low level and high level, the low level is represented by $(-1)$ and high level is represented by $(+1)$. The experimental layout for this experiment is shown in Table 4. The design matrix shows all the possible combinations of factors at their respective levels.

\section{Experimentation}

\section{Nanocomposite preparation by magnetic stirrer}

The uniform dispersion of MWCNTs in polymers is a big challenge, so ball milling, ultrasonication, magnetic stirring, and high speed mechanical stirring are the preferable processes for uniform dispersion of MWCNTs. According to the combinations designed in Table 4, the magnetic stirrer was operated for $20 \mathrm{~min}$ with a gradual speed increase from 30 to $320 \mathrm{rpm}$ with heating to about $40-80{ }^{\circ} \mathrm{C}$ as shown in Fig. 1. After $20 \mathrm{~min}$, the hardener was added to the dispersion for another $5 \mathrm{~min}$ with heating turned off. This epoxy resin was then applied on the

Table 2 List of process parameters and their levels

\begin{tabular}{llll}
\hline Process parameters & Labels & Low level $(-1)$ & High level $(+1)$ \\
\hline Weight of CNT & A & 0.25 gm & 0.5 gm \\
Process to disperse nano-particles in resin & B & Magnetic stirrer method & Probe sonicator method \\
Orientation of woven fabric & C & {$[0 / 0]_{\mathrm{s}}$} & {$[45 / 45]_{\mathrm{s}}$} \\
\hline
\end{tabular}


Table $42^{3}$ Two-level, full factorial design table showing actual settings of the process parameters

\begin{tabular}{llll}
\hline Experiment & A $(\mathrm{gm})$ & B (method) & C (sequence) \\
\hline 1 & 0.25 & Magnetic stirrer method (MSM) & {$[0 / 0 / 0 / 0]$} \\
2 & 0.5 & Magnetic stirrer method (MSM) & {$[0 / 0 / 0 / 0]$} \\
3 & 0.25 & Probe sonicator method (PSM) & {$[0 / 0 / 0 / 0]$} \\
4 & 0.5 & Probe sonicator method (PSM) & {$[0 / 0 / 0 / 0]$} \\
5 & 0.25 & Magnetic stirrer method (MSM) & {$[45 / 45 / 45 / 45]$} \\
6 & 0.5 & Magnetic stirrer method (MSM) & {$[45 / 45 / 45 / 45]$} \\
7 & 0.25 & Probe sonicator method (PSM) & {$[45 / 45 / 45 / 45]$} \\
8 & 0.5 & Probe sonicator method (PSM) & {$[45 / 45 / 45 / 45]$} \\
\hline
\end{tabular}

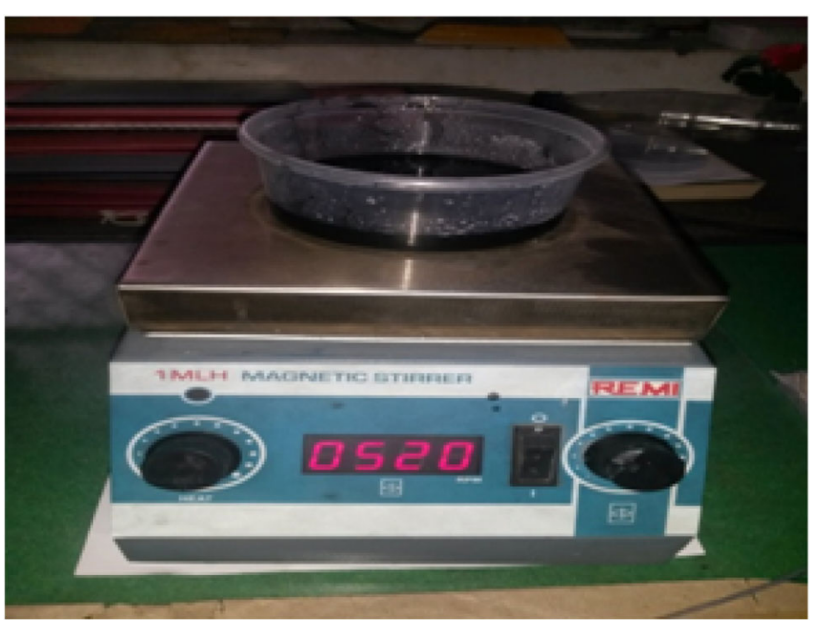

Fig. 1 Magnetic stirrer used for stirring purpose

fiberglass sheets by hand-layup method using the mold of $150 \times 150 \times 3 \mathrm{~mm}$ size and was left for proper curing. Hence, the four different combinations $(1,2,5$, and 6$)$ were prepared.

\section{Nanocomposite preparation by probe-based sonicator}

Apart from the earlier method of using a magnetic stirrer to prepare the matrix, as designed in Table 5 , the probe-based Sonicator is also used. Figure 2 shows the set up for probebased sonicator nano-particles mixing method. According to the combinations designed in Table 5, epoxy resin was first

Table 5 Specifications of probe sonicator

\begin{tabular}{lll}
\hline S. No. & Property & Value \\
\hline 1 & Amplitude & $70 \mu \mathrm{m}$ \\
2 & Frequency & $24 \mathrm{kHz}$ \\
3 & Pulse & 15 \\
4 & On/off time & $10 \mathrm{~s}$ \\
5 & Maximum operating temperature & $75{ }^{\circ} \mathrm{C}$ \\
\hline
\end{tabular}

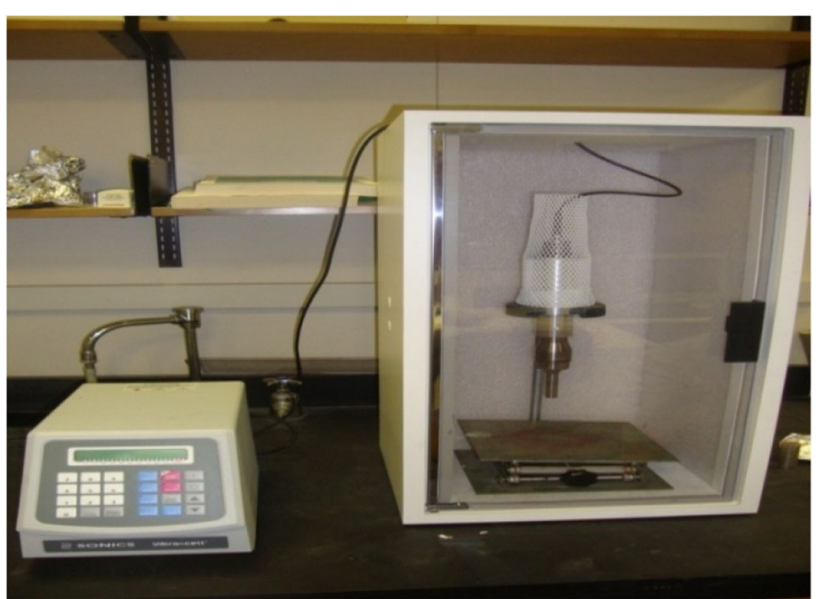

Fig. 2 Probe sonicator

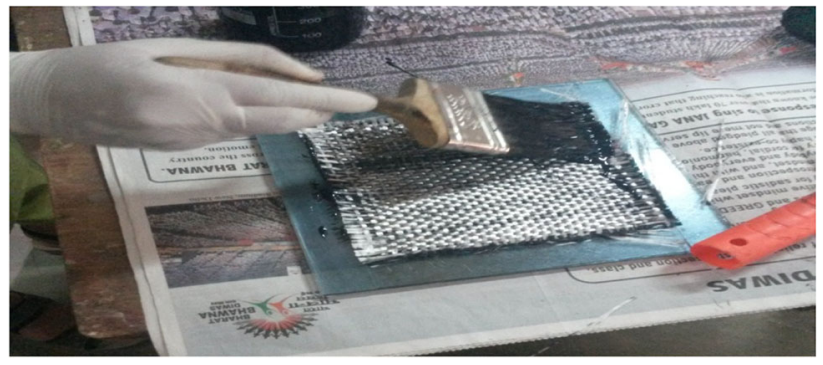

Fig. 3 Fabrication of nano-composite plates in a glass mold

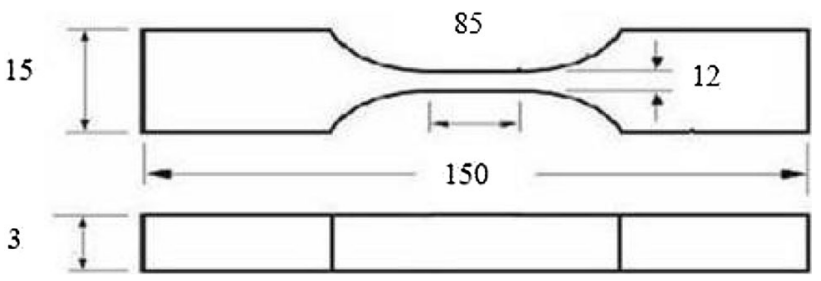

Fig. 4 Dimensions according to ASTM D3039-76 standards

mixed by mechanical stirring for $5 \mathrm{~min}$ with a glass rod. Then this mixture was sonicated for a total time of approximately $40 \mathrm{~min}$. The input given to the probe sonicator is as follows: 


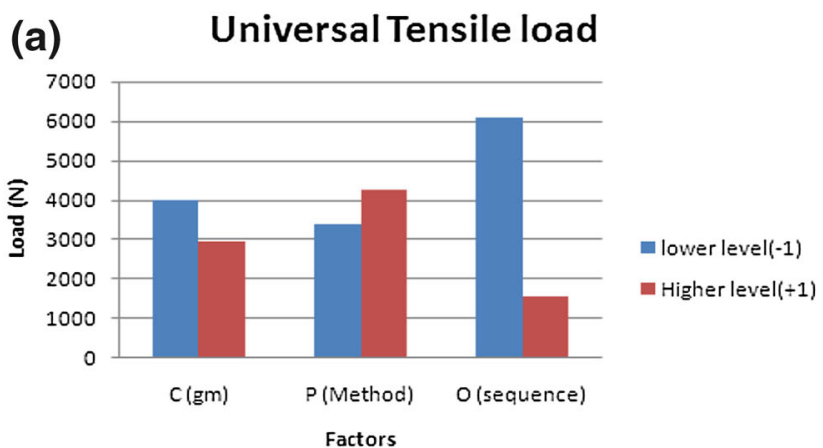

(c) Universal Tensile Strength

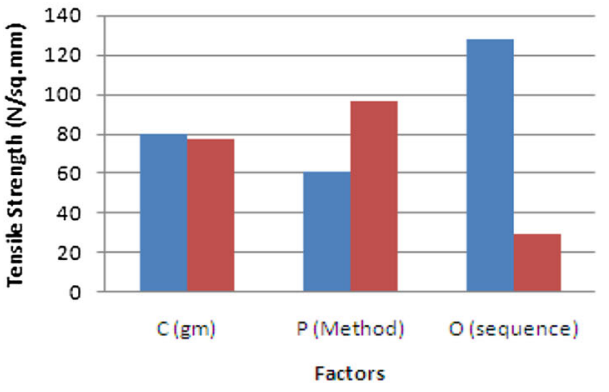

- Lower level (-1)

- Higher level (+1)

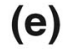

Yield Stress

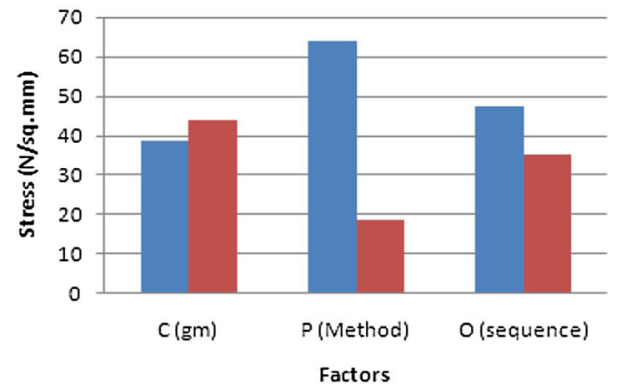

- lower level $(-1)$

- Higher level (+1)

Fig. 5 Effects of factors of fabricated nano-composite plate

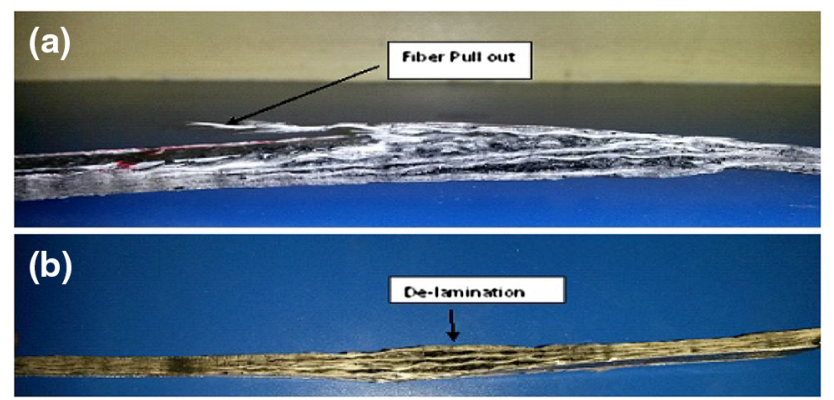

Fig. 6 Fiber-pull-out and delamination of the hybrid oriented composite laminate

This epoxy resin was the applied on the fiberglass sheets by hand-layup method using the mold of $150 \times 150 \times 3 \mathrm{~mm}$ size as shown in Fig. 3 and was left for proper curing. Hence, the four different combinations $(3,4,7$, and 8$)$ were prepared.

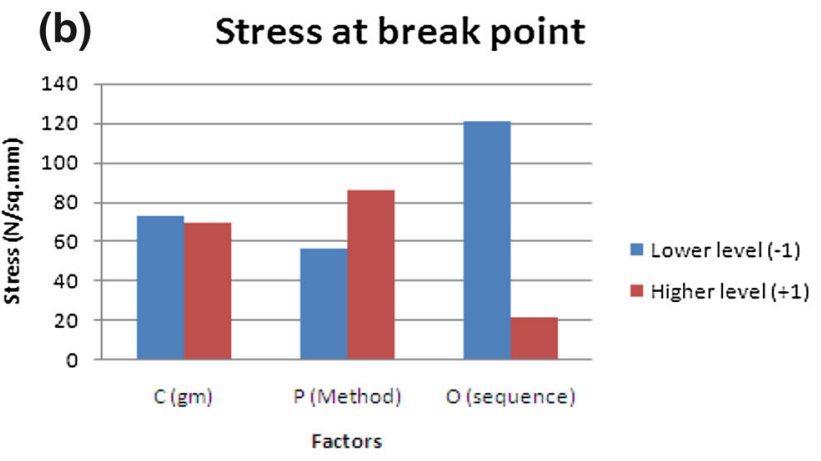

(d) Break Load
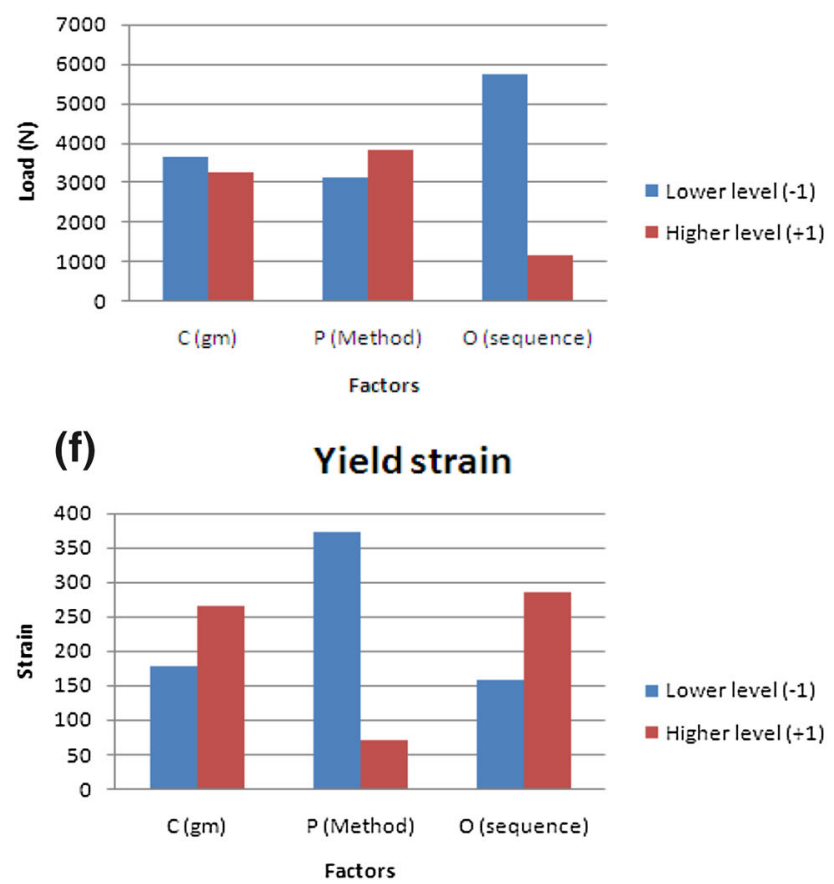

\section{Specimen preparation}

After the fabricated composite plate had been removed from the mold, the specimens were prepared according to ASTM D3039-76 standards (ASTM D 3029 1982). Individual specimens were cut out after marking them accordingly. Dimensions of the individual specimens are shown in Fig. 4 (Fig. 5).

\section{Results and discussion}

Tensile testing was carried out on the specimens using U.T.M. with cross head speed $10 \mathrm{~mm} / \mathrm{min}$ and the results were shown in Fig. 6. As observed from the test results, Fig. 6 indicates that maximum universal load-bearing capacity is observed with low level nanoparticles stirring 
Table 6 Tensile test results for nano-composites

\begin{tabular}{|c|c|c|c|c|c|c|c|c|c|}
\hline \multirow[t]{2}{*}{ S. No. } & \multicolumn{3}{|l|}{ Factors } & \multicolumn{6}{|l|}{ Results } \\
\hline & A (gm) & B (method) & $\mathrm{C}$ (sequence) & U.T.L (N) & $\begin{array}{l}\text { Stress at break } \\
\text { point }\left(\mathrm{N} / \mathrm{mm}^{2}\right)\end{array}$ & $\begin{array}{l}\text { U.T.S } \\
\left(\mathrm{N} / \mathrm{mm}^{2}\right)\end{array}$ & $\begin{array}{l}\text { Break load } \\
(\mathrm{N})\end{array}$ & $\begin{array}{l}\text { Yield stress } \\
\left(\mathrm{N} / \mathrm{mm}^{2}\right)\end{array}$ & $\begin{array}{l}\text { Yield strain } \\
(\mathrm{mm})\end{array}$ \\
\hline 1 & 0.25 & MSM & {$[0 / 0]_{\mathrm{s}}$} & 6070.4 & 97.70 & 105.00 & 5648.6 & 66.136 & 227.0 \\
\hline 2 & 0.5 & MSM & {$[0 / 0]_{\mathrm{s}}$} & 4725.5 & 91.99 & 92.11 & 4719.6 & 80.52 & 292.2 \\
\hline 3 & 0.25 & PSM & {$[0 / 0]_{\mathrm{s}}$} & 6830.7 & 147.9 & 157.4 & 6417.7 & 24.5 & 76.00 \\
\hline 4 & 0.5 & PSM & {$[0 / 0]_{\mathrm{s}}$} & 6728.7 & 144.1 & 156.8 & 6183.2 & 18.4 & 31.00 \\
\hline 5 & 0.25 & MSM & {$[45 / 45]_{\mathrm{s}}$} & 1254.2 & 17.7 & 20.7 & 1072.8 & 49.2 & 322.9 \\
\hline 6 & 0.5 & MSM & {$[45 / 45]_{\mathrm{s}}$} & 1471.8 & 15.7 & 23.4 & 986.7 & 59.5 & 644.4 \\
\hline 7 & 0.25 & PSM & {$[45 / 45]_{\mathrm{s}}$} & 1812.9 & 28.5 & 35.4 & 1458.7 & 14.9 & 84.0 \\
\hline 8 & 0.5 & PSM & {$[45 / 45]_{\mathrm{s}}$} & 1631.4 & 23.2 & 34.9 & 1080.1 & 16.6 & 88.0 \\
\hline
\end{tabular}

Table 8 Effects of factors of fabricated nano-composite plate

\begin{tabular}{|c|c|c|c|c|c|c|c|}
\hline S. No. & Description & U.T.L (N) & $\begin{array}{l}\text { Stress at break } \\
\text { point }\left(\mathrm{N} / \mathrm{mm}^{2}\right)\end{array}$ & U.T.S $\left(\mathrm{N} / \mathrm{mm}^{2}\right)$ & Break load $(\mathrm{N})$ & $\begin{array}{l}\text { Yield stress } \\
\left(\mathrm{N} / \mathrm{mm}^{2}\right)\end{array}$ & Yield strain $(\mathrm{mm})$ \\
\hline 1 & Sample 1 & 1631.40 & 23.16 & 34.99 & 1080.08 & 16.56 & 31.00 \\
\hline 2 & Sample 2 & 1812.88 & 28.50 & 35.43 & 1458.74 & 14.95 & 76.00 \\
\hline 3 & Sample 3 & 1405.03 & 28.31 & 31.67 & 1255.92 & 17.96 & 34.90 \\
\hline
\end{tabular}

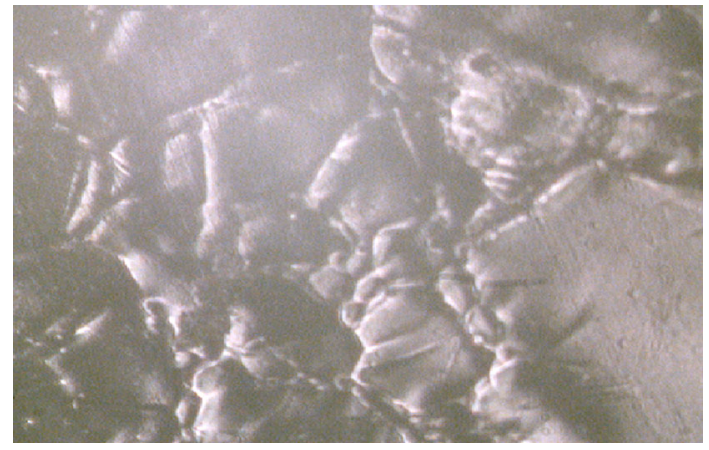

Fig. 7 Epoxy resin without nanoparticles

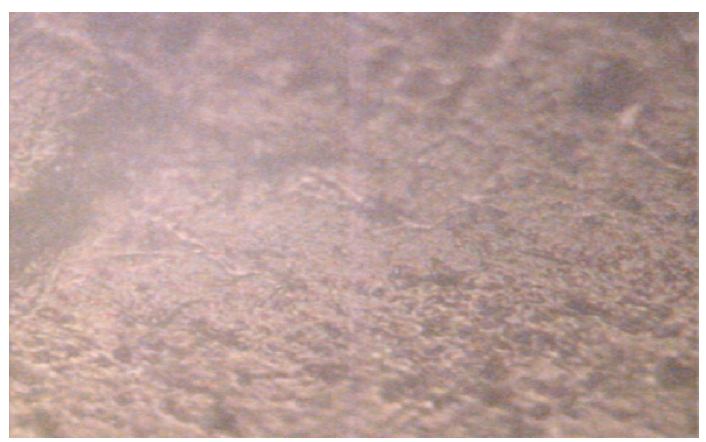

Fig. 8 Epoxy resin with MWCNT stirred by mechanical stirrer

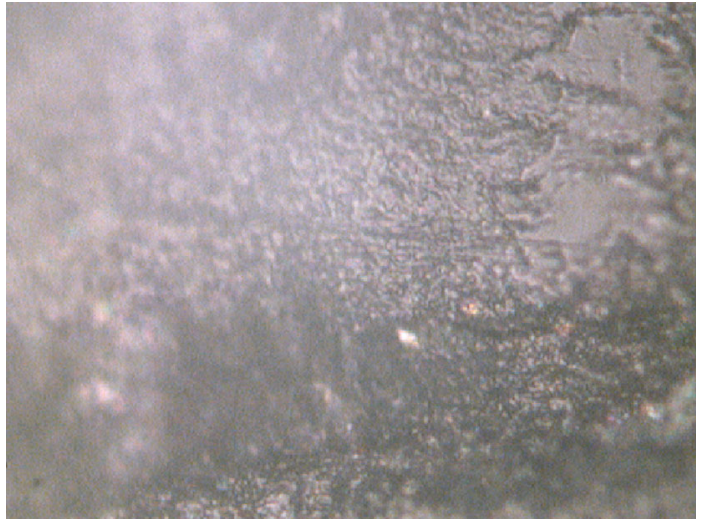

Fig. 9 Epoxy resin with MWCNT stirred by probe sonicator

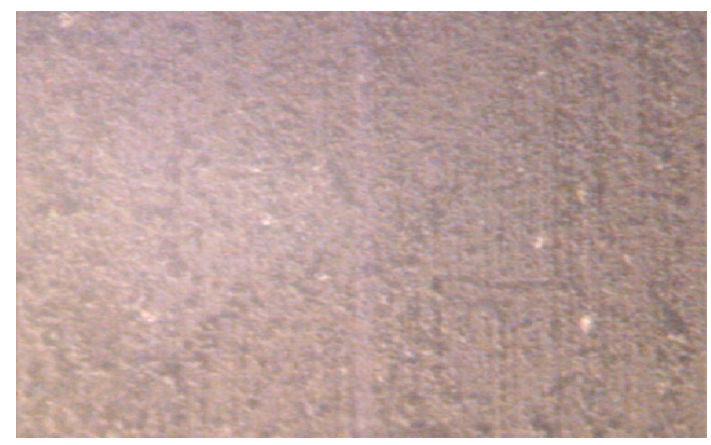

Fig. 10 E-glass/epoxy resin with MWCNT stirred by mechanical stirrer 


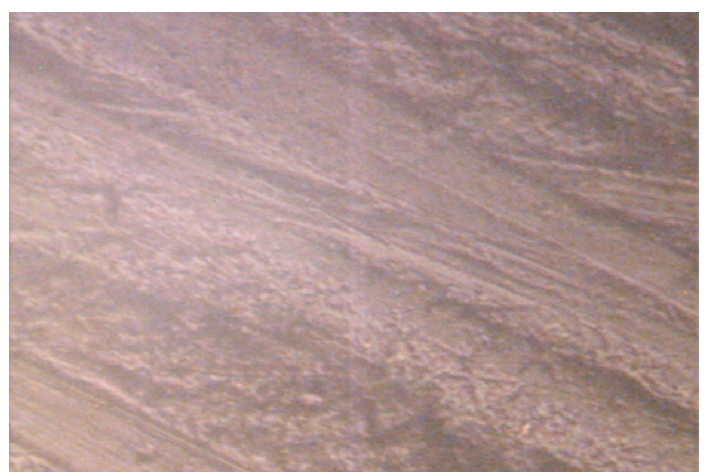

Fig. 11 E-Glass/Epoxy with MWCNT stirred by probe sonicator

by probe sonicator with ply-up orientation [0/0/0/0]. Maximum stresses at break point were indicated with low level nano-particles stirring by probe sonicator with ply-up orientation $[0 / 0 / 0 / 0]$, so that with these factors the life of the nano-composite plate is increased. The maximum tensile strength and maximum break-load capacity were also observed for low level nano-particles stirring by probe sonicator with ply-up orientation $[0 / 0 / 0 / 0]$. The maximum yield stresses were observed for higher level nano-particles stirring by magnetic stirrer with ply-up orientation $[0 / 0 / 0 /$ $0]$ whereas the minimum yield stresses were observed for low-level nano-particles stirring by probe sonicator with ply-up orientation [45/45/45/45]. The maximum yield strains were observed for high-level nano-particles stirring by magnetic stirrer with ply-up orientation [45/45/45/45] whereas the minimum yield stresses were observed for low-level nano-particles stirring by probe sonicator with ply-up orientation [0/0/0/0] (Table 6).

The test results for specimens prepared by magnetic stirring do not yield proper strength as required. The reasons may be improper dispersion of MWCNT's in the epoxy resin, due to heating the epoxy resin has lost its properties, improper bonding of the MWCNT's and epoxy resin with the fiber glass. Therefore, by observing the

E-Glass /Epoxy with MWCNT first layer Failure

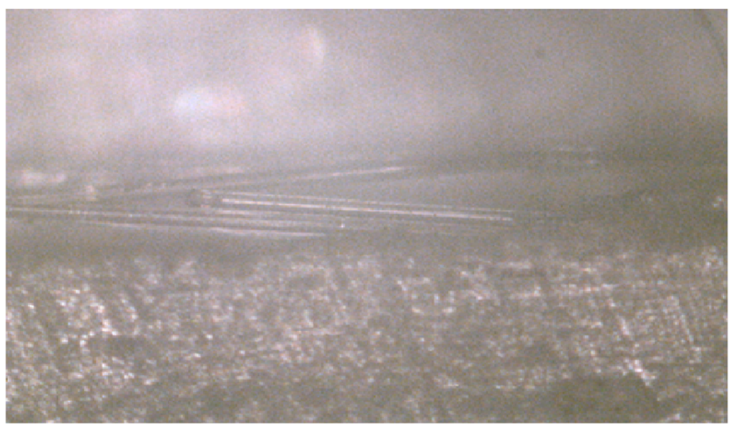

Fig. 12 E-glass/epoxy with MWCNT failure in layers above discussions it can be concluded that for minimum yield stresses and strains the nano-particulated composite plate can be manufactured by considering lower level nano-particles stirred with probe sonicator and plied-up with hybrid orientation. Hence, hybrid orientation for confirmation test is carried out with ply-up sequence [0/45/ 45/0]. The test results of the fabricated plate are shown in Table 7.

The confirmation test indicates that the suggested orientation shows better performance regarding maximum yield stresses and strains. The individual fiber-pull-out was observed in the de-laminated specimens.

The microstructures of the epoxy resin without nanoparticles, epoxy resin with MWCNT stirred by mechanical stirrer and stirred by probe sonicater, E-glass/ epoxy resin with MWCNT stirred by mechanical stirrer and by probe sonicator and failure in layers of E-glass/ epoxy with MWCNT are shown in Fig. 7-12.

\section{Conclusions}

The fabricated polymer composites with variations in the preparation of matrix with carbon nanotubes was successfully fabricated and tested using hand layup method at room temperature. The experiments on tensile tests conducted with the chosen E-glass fiber and carbon nanotube enhancements show that there will be an increase in universal tensile strength when properly dispersed and also can sustain greater break loads. By the test results achieved, we find that dispersion of the carbon nanotubes in the epoxy resin plays a major role in deciding the strength factor the composite material will have. It tends to create that bonding between the matrix and the E-glass fiber sheets which help increase the tensile strength of the composite material. Proper dispersion results in the proper bonding of the carbon nanotubes with individual fibers. It is observed that the delamination and fiber breakage are

E-Glass /Epoxy with MWCNT second layer

Failure

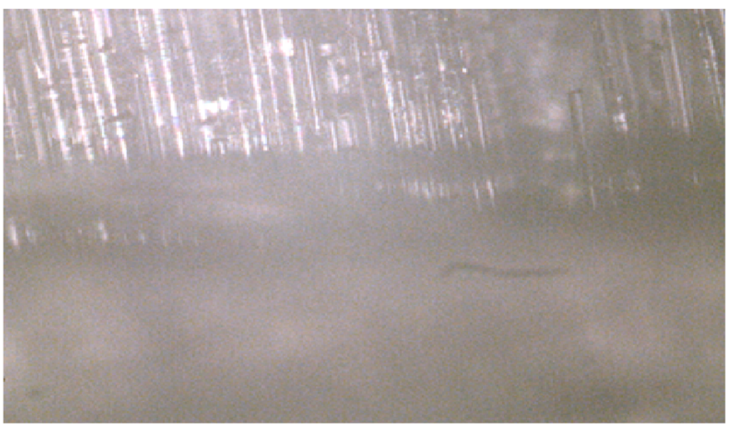


minimal when the carbon nanotubes are properly dispersed using a probe sonicator rather than the magnetic stirrer. The fiber-pull-out and delamination are observed majorly in the $0^{\circ}$ oriented specimens against the $45^{\circ}$ specimens where delamination and fiber-pull-out was minimal. By observing the above discussions it can be concluded that for minimum yield stresses and strains the nano-particulated composite plate can be manufactured by considering lower level nano-particles stirred with probe sonicator and plied-up with hybrid orientation. Hence hybrid orientation for confirmation test is carried out with ply-up sequence [0/ $45 / 45 / 0]$. The confirmation test indicates that the suggested orientation shows better performance regarding maximum yield stresses and strains.

Open Access This article is distributed under the terms of the Creative Commons Attribution 4.0 International License (http:// creativecommons.org/licenses/by/4.0/), which permits unrestricted use, distribution, and reproduction in any medium, provided you give appropriate credit to the original author(s) and the source, provide a link to the Creative Commons license, and indicate if changes were made.

\section{References}

Abrate S (1991) Impact on laminated composite materials. Appl Mech Rev 44(4):155-189
ASTM D 3029 (1982) Standard test method for impact resistance of rigid plastic sheeting or parts by means of a tup (falling weight). American Society for Testing and Materials, Philadelphia

Bibo GA, Hogg PJ (1996) Review-the role of reinforcement architecture on impact damage mechanisms \& post-impact compression behavior. J Mater Sci 31:1115-1137

Cantwell WJ, Morton J (1991) The impact resistance of composite materials-a review. Compos A 22:347-362

Choi HY, Downs RJ, Chang FK (1991) A new approach toward understanding damage mechanism and mechanics of laminated composites due to low-velocity impact. J Compos Mater 25:992-1011

Davies GAO, Hitchings D, Zhou G (1996) Impact damage and residual strengths of woven fabric glass/polyester laminates. Compos A 27A:1147-1156

Ebeling T, Hiltner A, Baer E, Fraser IM, Orton ML (1997) Delamination failure of a woven glass fiber composite. J Compos Mater 31:1318-1333

Hirai Y, Hamada H, Kim JK (1998a) Impact response of woven glass fabric composites- - , effect of fiber surface treatment. Compos Sci Technol 58:91-104

Hirai Y, Hamada H, Kim JK (1998b) Impact response of woven glass fabric composites-II, effect of temperature. Compos Sci Technol 58:119-128

Lifshitz JM, Gandelsman M (1997) Effect of near-surface impactinduced damage on the residual strength of woven glass/epoxy composite beams. Compos Sci Technol 57:205-216

Naik NK et al (2000) Damage in woven-fabric composites subjected to low-velocity impact. Compos Sci Technol 60:731-744

Richardson MOW, Wisheart MJ (1996) Review of low-velocity impact properties of composite materials. Compos A 27A:1123-1131 